\title{
SISTEM PENERIMAAN PESERTA DIDIK BARU BERBASIS JAVA PADA SDN GANDARIA SELATAN 03
}

\author{
Boni Pasius Dolok Saribu', Thomas Afrizal'2, Tria Hadi Kusmanto ${ }^{3}$ \\ ${ }^{1,2,3}$ Teknik Informatika, Fakultas Teknik dan Ilmu Komputer, Universitas Indraprasta PGRI \\ Jalan Raya Tengah No 80, Kelurahan Gedong, Pasar Rebo, Jakarta Timur

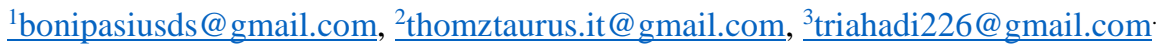

\begin{abstract}
ABSTRAK
Pada proses dan sistem penerimaan calon siswa baru pada SDN Gandaria Selatan 03 masih menggunakan perekrutan secara manual dan tradisional. Calon siswa yang ingin melakukan pendaftaran dirasakan oleh pendaftar masih kurang efisien dan praktis. Selain itu, waktu yang dibutuhkan untuk memproses data penerimaan calon siswa siswa lebih lama. Untuk menyelesaikan masalah tersebut, dilakukan suatu penelitian dengan tujuan dibangun suatu sistem yang dapat membantu pihak sekolah dalam proses penerimaan peserta didik baru agar lebih mudah dan efesien. Dalam membangun sistem, penulis menggunakan metode Waterfall yaitu suatu pendekatan paling awal yang digunakan untuk pengembangan perangkat lunak. Urutan dalam Metode Waterfall bersifat serial yang dimulai dari proses perencanaan, analisa, desain, dan implementasi pada sistem. sedangkan sistem terkomputerisasi menggunakan Java Netbeans. Hasil dari penelitian yang dilakukan di SDN Gandaria Selatan 03, terciptanya suatu sistem penerimaan calon siswa baru yang lebih tepat, cepat, efektif dan mampu menyelesaikan permasalahan yang ada.
\end{abstract}

Kata Kunci : Sistem Penerimaan, Siswa Baru, Java Netbeans, Waterfall

\section{ABSTRACT}

In the process and system of accepting new prospective students at SDN Gandaria Selatan 03, they still use manual and traditional recruitment. Prospective students who want to register are felt by the registrants are still less efficient and practical. In addition, the time required to process data on student admissions is longer. To solve this problem, a study was conducted with the aim of building a system that can help the school in the process of accepting new students to make it easier and more efficient. In building the system, the author uses the Waterfall method, which is the earliest approach used for software development. The sequence in the Waterfall Method is serial, starting from the planning, analysis, design, and implementation processes on the system. while the computerized system uses Java Netbeans. The results of the research conducted at SDN Gandaria Selatan 03, the creation of a new student admission system that is more precise, fast, effective and able to solve existing problems.

Key Word : Admission System, New Students, Java Netbeans, Waterfall

\section{PENDAHULUAN}

Proses penerimaan peserta didik baru dengan menggunakan suatu sistem yang terkoneksi internet di Indonesia memang sudah cukup populer dan banyak digunakan. Namun tidak dengan proses penerimaan siswa pada sekolah dasar (SD). Menurut (Neyfa \& s Salsabila, 2016), pendekatan sistem yang menekan pada prosedurnya, "Definisi sistem adalah suatu jaringan kerja dan prosedur-posedur yang saling berhubungan, berkumpul bersamasama untuk melakukan suatu kegiatan atau untuk menyelesaikan sasaran tertentu". Dalam proses peneriman siswa baru dikalangan sekolah dasar cukup rumit dan banyak menyita waktu, terlebih lagi siswa SD yang tergolong masih anak-anak belum mampu untuk melakukan pendaftaran secara mandiri dan tentu membutuhkan banyak peran orang tua. Penerimaan yang dilakukan secara online dapat memudahkan proses penerimaan dengan lebih efisien dan transparan, dengan manfaat dan kemudahan yang ada, sudah seharusnya sistem ini di kembangkan oleh tiap-tiap sekolah. Hal ini sejalan dengan kemajuan teknologi informasi dan komunikasi seperti internet dan web yang mampu mendukung proses input dan output secara cepat dan akurat, khusus nya dalam pelaksanaan PSB.

Penulis membatasi permasalahan yang dapat di identifikasi dari beberapa permasalahan yang muncul antara lain :1) Rawan terjadinya praktik kecurangan pada pelaksanaan penerimaan peserta didik baru secara manual yang melibatkan sejumlah pihak, seperti peserta, orang tua peserta, maupun panitia 
penerimaan siswa baru. 2) Rumitnya proses pendataan, administrasi dan informasi pada pelaksanaan PSB secara manual yang mengakibatkan kurang efisiennya pengguanaan waktu, tempat, biaya maupun tenaga.

Adanya permasalahan tersebut penulis membuat sistem yang berdasarkan aplikasi untuk dapat membantu sekolah maupun para orang tua yang akan melakukan pendaftaran secara praktis dan efisien. Sistem penerimaan peserta didik baru yang menggunakan bahasa pemrograman Java netbean yang mampu mengelola data dalam proses pelaksanaan penerimaan peserta didik baru yaitu pendaftaran, pengumpulan data, pengumuman dan hasil penerimaan.

(Mufidah \& Jannah, 2017), "Sistem dapat didefinisikan dengan pendekatan prosedur dan pendekatan komponen, sistem dapat didefinisikan sebagai kumpulan dari prosedur-prosedur yang mempunyai tujuan tertentu". Adapun pendekatan sistem yang menekankan pada elemen atau komponennya, sistem adalah kumpulan dari elemen-elemen yang berinteraksi untuk mencapi suatu tujuan.

"Model umum sebuah sistem adalah input, proses, dan output. Hal ini merupakan konsep sebuah sistem yang sangat sederhana sebab sebuah sistem dapat mempunyai beberapa masukan dan keluaran. Selain itu, sebuah sistem mempunyai karakteristik atau sifatsifat tertentu yang mencirikan bahwa hal tersebut bisa dikatakan sebagai suatu sistem" (Fatchan, 2017)

Penelitian ini dapat memberikan manfaat dalam pengelolahan data dalam proses penerimaan peserta didik baru pada SDN Gandaria Selatan 03.

\section{METODE PENELITIAN}

Penulis menggunakan metode penelitian waterfall yaitu suatu pendekatan paling awal yang digunakan untuk pengembangan perangkat lunak. Menurut (Risald, 2021) model waterfall adalah model klasik yang bersifat sistematis, berurutan dalam membangun software. Urutan dalam Metode Waterfall bersifat serial yang dimulai dari proses perencanaan, analisa, desain, dan implementasi pada sistem. suatu metode penelitian berdasarkan pada fakta dan menggunakan analisis perbandingan.

(Cahyadi \& Susanto, 2020) adalah model klasik yang bersifat sistematis, berurutan dalam membangun software.

Langkah-langkah dalam metode penelitian yang dipakai penulis dalam pengembangan sistem antara lain identifikasi masalah, analisa kebutuhan sistem, merancang sistem, mengembangkan sistem, evaluasi awal sistem, implementasi dan evaluasi sistem, pengujian dan simpulan

\section{HASIL DAN PEMBAHASAN}

Sesuai dengan permasalahan makan penulis mengambil suatu metode pembangunan aplikasi yaitu dengan menggunakan metode Unified Modelling Language (UML) yang merupakan suatu Sistem Yang Diusulkan pada aplikasi yang dibangun. Unified Modeling Language menurut (Haerulah \& Ismiyatih, 2017) adalah satu set peragaan konvensi yang digunakan untuk menetapkan atau menguraikan suatu sistem perangkat lunak dalam bentuk obyek.

Sesuai dengan permasalahan diatas maka peneliti menggunakan pendekatan dan penjelasan sistem yang berorientasi objek yakni dengan membuat penjelasan menggunakan metode use case diagram ,use case skenario, activity diagram, sequence diagram, dan class diagram untuk diharapkan mempu memberikan penjelasan yang cukup baik. Penjelasan tersebut akan dibahas berikut ini.

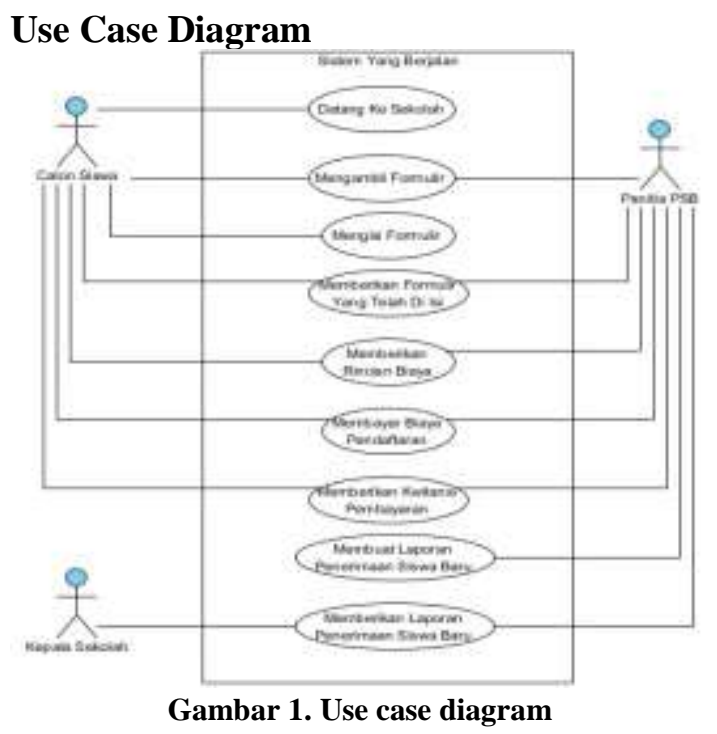


1. Identifikasi aktor

a. Panitia

Bagian yang menangani, menginput dan memproses data yang ada di aplikasi data calon siswa.

b. Ketua panitia

Orang yang bertanggung jawab terhadap kinerja para pekerja dan melihat laporan semua data yang ada.

2. Identifikasi diagram use case

Tabel 1. Identifiksi Diagram Use Case

\begin{tabular}{|c|c|c|c|}
\hline No & $\begin{array}{l}\text { Use case } \\
\text { name }\end{array}$ & Description & Aktor \\
\hline 1 & Login & $\begin{array}{l}\text { Use case } \\
\text { menggambarkan } \\
\text { kegiatan input } \\
\text { username dan } \\
\text { password }\end{array}$ & $\begin{array}{c}\text { Panitia } \\
\text { PSB }\end{array}$ \\
\hline 2 & $\begin{array}{l}\text { Input data } \\
\text { calon } \\
\text { siswa }\end{array}$ & $\begin{array}{l}\text { Use case } \\
\text { menggambarkan } \\
\text { kegiatan } \\
\text { pengolahan data } \\
\text { siswa yang masuk } \\
\text { kedalam aplikasi }\end{array}$ & $\begin{array}{l}\text { Calon } \\
\text { Siswa }\end{array}$ \\
\hline 3 & $\begin{array}{l}\text { Input } \\
\text { Berkas } \\
\text { calon } \\
\text { siswa }\end{array}$ & $\begin{array}{l}\text { Use case } \\
\text { menggambarkan } \\
\text { kegiatan } \\
\text { pengolahan } \\
\text { berkas calon } \\
\text { siswa ke dalam } \\
\text { sistem } \\
\end{array}$ & $\begin{array}{l}\text { Calon } \\
\text { Siswa }\end{array}$ \\
\hline 4 & $\begin{array}{c}\text { Input } \\
\text { pembayar } \\
\text { an calon } \\
\text { siswa }\end{array}$ & $\begin{array}{l}\text { Use case } \\
\text { menggambarkan } \\
\text { penginputan data } \\
\text { pembayaran uang } \\
\text { pendaftaran awal }\end{array}$ & $\begin{array}{l}\text { Calon } \\
\text { Siswa }\end{array}$ \\
\hline 5 & $\begin{array}{l}\text { Input data } \\
\text { hasil } \\
\text { perekrutan }\end{array}$ & $\begin{array}{l}\text { Use case } \\
\text { menggambarkan } \\
\text { pengolahan data } \\
\text { hasil penerimaan } \\
\text { pesrta didik baru } \\
\text { ke dalam sistem }\end{array}$ & Panitia \\
\hline 6 & $\begin{array}{l}\text { Mencetak } \\
\text { laporan } \\
\text { hasil } \\
\text { penerimaa } \\
\text { n siswa } \\
\text { baru }\end{array}$ & $\begin{array}{l}\text { Use case } \\
\text { menggambarkan } \\
\text { kegiatan dalam } \\
\text { mencetak laporan } \\
\text { hasil peneriman } \\
\text { siswa baru }\end{array}$ & $\begin{array}{c}\text { Panitia } \\
\text { PSB }\end{array}$ \\
\hline 7 & $\begin{array}{c}\text { Mencetak } \\
\text { laporan }\end{array}$ & $\begin{array}{l}\text { Use case } \\
\text { menggambarkan } \\
\text { kegiatan dalam } \\
\text { mencetak laporan } \\
\text { penerimaan calon } \\
\text { siswa }\end{array}$ & $\begin{array}{c}\text { Panitia } \\
\text { PSB }\end{array}$ \\
\hline
\end{tabular}

\section{Activity Diagram}

Activity diagram merupakan suatu proses pembangunan sebuah aplikasi yang dimana cara kerja nya berfokus pada alur (work flow). Menurut (Dharmawan et al., 2018) "Activity
Diagram menggambarkan aktivitas utama dari user pada sistem informasi yang dibuat". Disimpulkan dari dua penjelasan diatas bahwa Activity Diagram teknik untuk mendeskripsikan logika prosedural, proses bisnis dan aliran kerja dalam banyak kasus. Diagram ini sangat mirip dengan flowchart karena dengan activity diagram dapat memodelkan proses logika, proses bisnis dan alur kerja. Perbedaan utamanya adalah flowchart dibuat untuk menggambarkan alur kerja dari sebuah sistem, sedangkan activity diagram dibuat untuk menggambarkan aktivitas aktor.

Dibawah ini adalah activity diagram untuk input login :

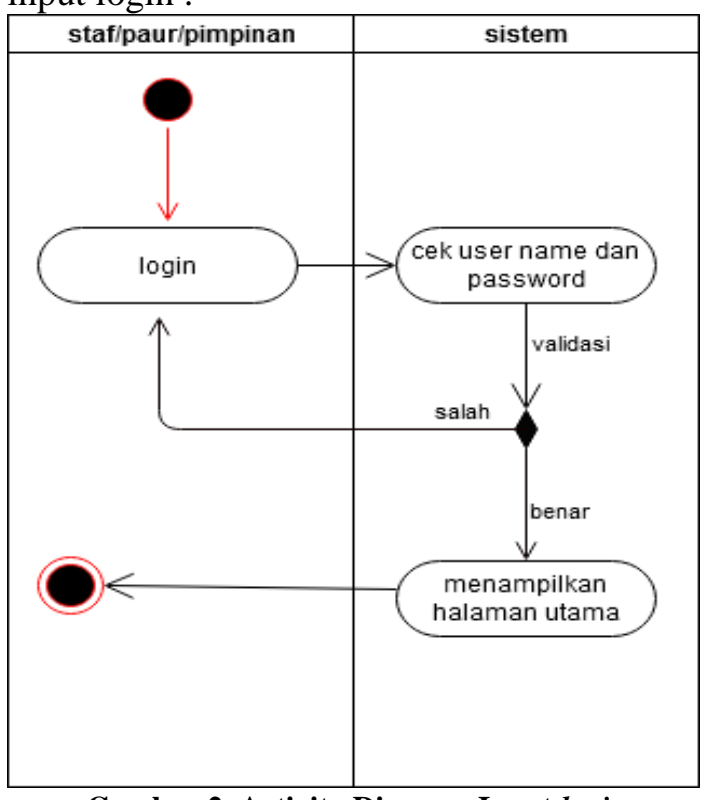

Gambar 2. Activity Diagram Input login

Gambar 2 adalah activity diagram input login yang menjelaskan aktor staf dan paur/pimpinan melakukan pengisian username dan password pada menu login. Jika username dan password yang dimasukkan salah, maka sistem akan menampilkan peringatan login gagal. Dan jika benar, maka sistem akan menampilkan halaman utama (home) sistem dan selanjutnya user dapat mengakses menu-menu yang disediakan sistem sesuai level masing-masing. Menurut (Widianto \& Putri, 2018) diagram aktivitas atau activity diagram adalah menggambarkan aliran kerja atau aktifitas dari sebuah sistem atau proses bisnis atau menu yang ada pada perangkat lunak. Diagram aktifitas menggambarkan aktifitas sistem bukan apa yang dilakukan oleh aktor. 


\section{Sequence Diagram}

Sequence diagram merupakan suatu metode penjelasan diagram yang digunakan untuk menunjukkan dan menjelaskan interaksi antara objek yang saling berhubungan secara detail. Sequence diagram juga sering disebut diagram urutan. Kegunaannya untuk menunjukan rangkaian pesan yang dikirim antara objek juga interaksi antara objek, sesuatu yang terjadi pada titik tertentu dalam eksekusi sistem.

Setiap sistem memiliki proses dan setiap proses memiliki dua kriteria yaitu proses sederhana dan kompleks. Dengan demikian tidak seluruh proses pada sistem akan ditampilkan pada sequence diagram, melainkan hanya garis besarnya saja.

Menurut (Anna \& Arissusandi, 2019) "Sequence Diagram menggambarkan bagaimana sistem merespon kegiatan user. Sequence Diagram yang dibuat yaitu yang berhubungan langsung dengan kegiatan utama dari sistem informasi anggaran pendapatan dan belanja desa berbasis objek".

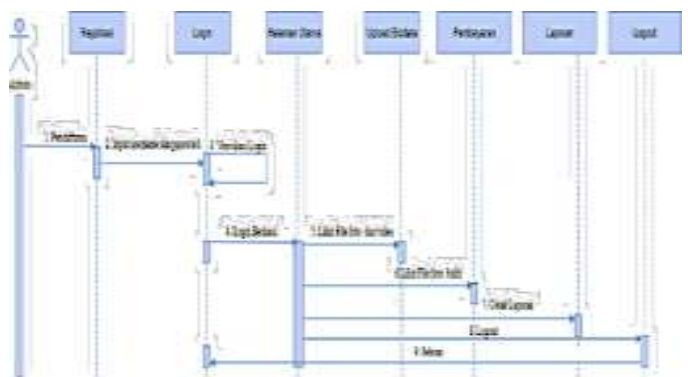

Gambar 3. Sequence Diagram Menu Login

Pada gambar 3 menjelaskan calon siswa melakukan pengisian username dan password pada menu login. Sistem akan melakukan verifikasi data dengan data yang tersimpan di dalam database. Apabila data yang diinput sudah sesuai maka sistem akan menampilkan halaman utama (home). Kemudian untuk selanjutnya pengguna dapat mengakses atau memilih menu yang tersedia pada sistem untuk melakukan proses penaftaran selanjutnya.

\section{Class Diagram}

Class diagram menggambarkan struktur dan deskripsi class, package, dan objek yang saling terhubung. Pada program ini di jelaskan bahwa class diagram yang dijelaskan berikut sesuai dengan sistem yang dibangun. Gambar dibawah ini menjelaskan class diagram sistem secara umum yang terdapat pada sistem program.

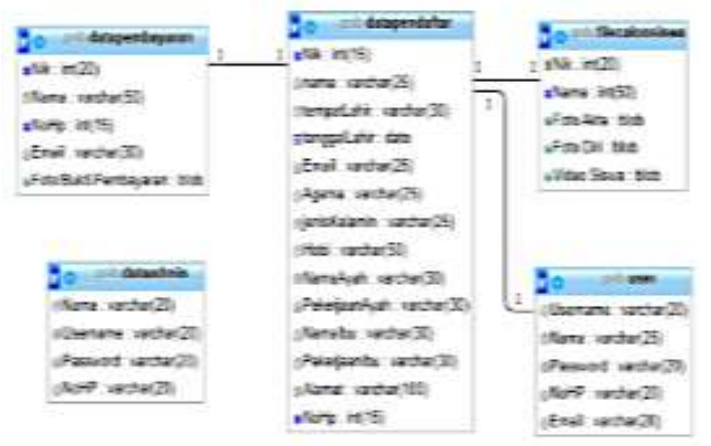

Gambar 4. Class Diagram

Menurut (Pratama\&Kurniadi,2021)

mendefinisikan: Class Diagram adalah diagram yang digunakan untuk mempresentaksikan kelas komponen-komponen kelas dan hubungan antara masing-masing kelas.

\section{Rancangan Layar}

Rancangan form login

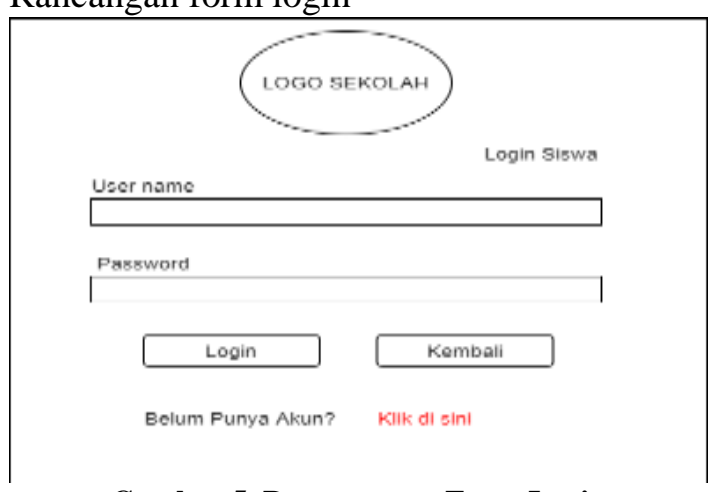

Gambar 5. Perancangan Form Login

Pada halaman login calon siswa peletakan field sejajar dengan logo dan tombol pendaftaran, Selain lebih menarik hal tersebut juga lebih mudah dipahami oleh calon siswa.

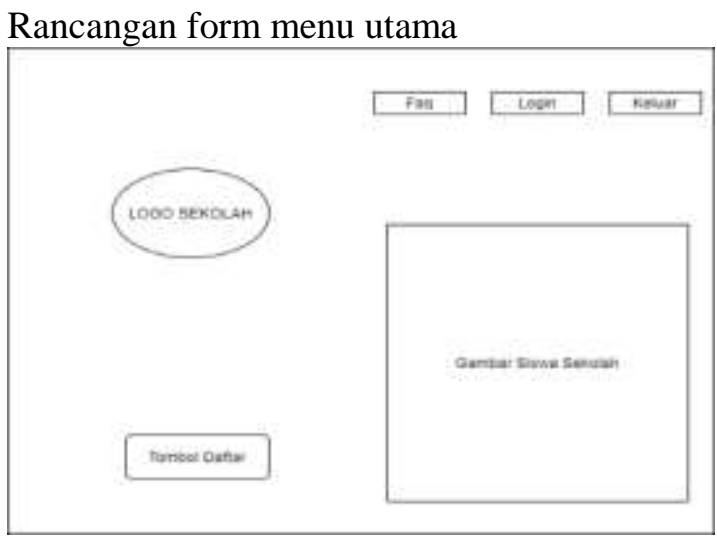

Gambar 6. Perancangan Form Menu Utama 
Semua judul form terletak pada pojok kanan atas agar lebih terlihat jelas dan minimalis. Label username, password, dan combo button bagian terletak kiri layar. Agar user lebih mudah untuk mengecek data yang telah dimasukan.

Halaman Login

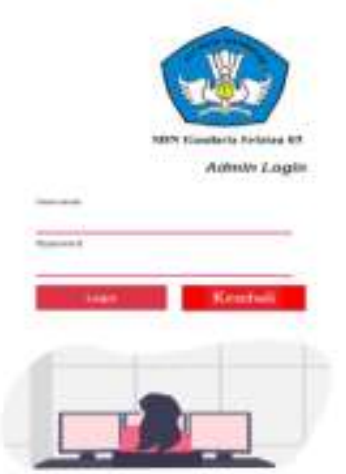

Gambar 7. Halaman Login

Pada form login siswa juga memiliki desain yang sama, user harus memasukan username dan password untuk dapat menggunakan program

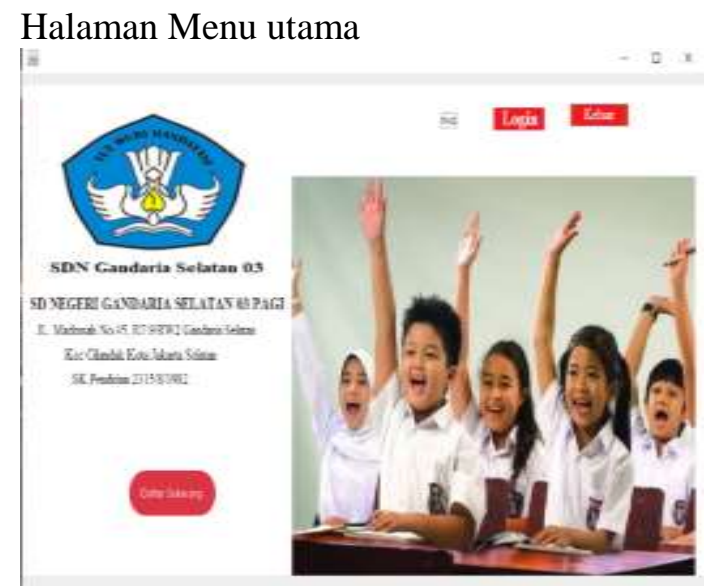

Gambar 8. Halaman Menu Utama

Pada halaman utama program terlihat ada logo dan gambar stiker yang membuat tampilan lebih baik dan menarik. Tombol terletak di sisi kiri bawah dan sisi kanan untuk mendukung tampilan dan kemudahan dalam pencarian form.

\section{SIMPULAN DAN SARAN}

Berdasarkan penelitian yang telah dilakukan bahwa penelitian pada sistem penerimaan siswa baru SDN Gandaria Selatan 03 Pagi maka peneliti dapat menyimpulkan beberapa kesimpulan yang dapat dijelaskan sebagai berikut:
Sistem penerimaan siswa baru yang berjalan saat ini pada SDN Gandaria Selatan 03 Pagi masih manual, yaitu masih menggunakan formulir penerimaan siswa baru yakni calon siswa mengisi data diri secara lengkap pada formulir penerimaan siswa baru yang telah disediakan sehingga dalam proses pengerjaannya membutuhkan waktu yang cukup lama, dengan metode seperti ini rawan terjadi kesalahan dalam proses seleksi dan pengumpulan data calon siswa.

Sistem yang berjalan di SDN Gandaria Selatan 03 Pagi masih menggunakan sistem yang manual, dan memakan banyak waktu untuk mengola data siswa yang mendaftar dan seringnya terjadi kesalahan-kesalahan dalam hal pengolahan data. Dengan merancang sistem penerimaan siswa baru yang efektif dan efisien pada SDN Gandaria Selatan 03 Pagi adalah menggunakan sistem komputer berbasis web yang di desain agar sistem yang didapat lebih efektif dan efisien.

Membuat sistem penerimaan siswa baru berbasis website pada SDN Gandaria Selatan 03 Pagi dengan adanya sistem baru yang sudah terkomputerisasi atau website diharapkan laporan penerimaan siswa baru berjalan lebih efektif dan efisien

Berdasarkan hasil penelitian dan analisis yang dilakukan oleh peneliti mengenai sistem penerimaan siswa baru pada SDN Gandaria Selatan 03 Pagi maka terdapat beberapa saran yang dapat dijadikan masukkan untuk meningkatkan kinerja, yaitu sebagai berikut: Untuk memaksimalkan pemanfaatan sistem yang dibuat maka dapat dilakukan pelatihan bagi staff yang menjadi panitia PPDB agar menjadi lebih memahami sistem yang ada. Memerlukan pencadangan data untuk menghindari kehilangan maupun kerusakan data yang masih diperlukan. Dilakukan pengembangan sistem yang baru untuk mengikuti perkembangan teknologi dimasa mendatang.

\section{DAFTAR PUSTAKA}

Anna, A., \& Arissusandi, R. (2019). Rancang Bangun Sistem Informasi Akuntansi Laporan Laba Rugi Berbasis Web Pada PT. United Tractors Pontianak. EVOLUSI: Jurnal Sains Dan Manajemen, 7(2). 
Cahyadi, C. M., \& Susanto, G. (2020). Rancang Bangun Sistem Informasi Bimbingan Konseling Di SMK Tamansiswa Mojokerto Berbasis Web Menggunakan Model Waterfall. RAINSTEK: Jurnal Terapan Sains \& Teknologi, 2(1), 61-70.

Dharmawan, W. S., Purwaningtias, D., \& Risdiansyah, D. (2018). Penerapan metode SDLC waterfall dalam perancangan sistem informasi administrasi keuangan berbasis desktop. Jurnal Khatulistiwa Informatika, 6(2).

Fatchan, M. (2017). Aplikasi Sistem Informasi Pemesanan Tiket Bus Pada PO. Rosalia Indah Berbasis Delphi. Jurnal SIGMA, 6(1), 64-74.

Haerulah, E., \& Ismiyatih, S. (2017). Aplikasi E-Commerce Penjualan Souvenir Pernikahan Pada Toko "XYZ." PROSISKO: Jurnal Pengembangan Riset Dan Observasi Sistem Komputer, 4(1).

Mufidah, F., \& Jannah, M. M. (2017). Efektivitas Sistem Informasi Akuntansi Pada Sistem Pembayaran SPP di Pondok
Pesantren La Tansa. Jurnal Studia Akuntansi Dan Bisnis, 5(2).

Neyfa, B. C., \& s Salsabila, G. (2016). Perancangan Aplikasi E-Canteen Berbasis Android Dengan Menggunakan Metode Object Oriented Analysis \& Design (OOAD). Jurnal Penelitian Komunikasi Dan Opini Publik, 20(1).

Pratama, Y. W., \& Kurniadi, D. (2021). Implementasi Blockchain dalam Aplikasi Pemilu. Incare, International Journal of Educational Resources, 2(2), 242-254.

Risald, R. (2021). Implementasi Sistem Penjualan Online Berbasis E-Commerce Pada Usaha Ukm Ike Suti Menggunakan Metode Waterfall. Journal of Information and Technology, 1(1), 3742.

Widianto, K., \& Putri, A. J. (2018). Sistem Informasi Akuntansi Buku Besar Menggunakan Metode Waterfall Studi Kasus CV. Sinar Abadi Jaya Jakarta. Bianglala Informatika, 6(1), 44-50. 